\title{
Introdução à Revisão Tipográfica (*)
}

\author{
Rivadávia Platão de Azambuja
}

\begin{abstract}
O autor, tendo feito minucioso estudo sôbre Revisão Tipográfica, extraiu de seu trabalho o artigo que agora publicamos, certos de que expressa uma orientação segura aos que se interessam pelo assunto. (NOTA DA REDAÇAO.)
\end{abstract}

\section{PRELIMINAR}

\section{$\mathrm{N}$ dir do trabalho do revisor.}

Desde as mais modestas, aquelas que sòmente logram dispor de uma estante de tipos e de uma máquina minerva, até as de grandes recursos, aquelas que se gabam de contar com as mais modernas instalações, a tôdas é indispensável o trabalho do revisor, para que a sua produção - isenta dos senões que a humana imperfeição é capaz de corrigir - possa ser considerada pelo
menos boa.

As primeiras, por causa das suas limitações, quase sempre se valem do próprio tipógrafo, auxiliado pelo cliente, para atingir êsse objetivo; as últimas, dispondo de amplas possibilidades, utilizam-se da experiência de um corpo de revisores suficientemente versados em letras e em tipografia, para alcançar a mesma fina-

\section{ESQUEMAS}

Mostramos, a seguir, alguns esquemas de oficinas gráficas, não só para dar uma idéia de conjunto dos seus diversos setores e subsetores, como para nêles situar o setor da Revisão. * Extraído da obra «Revisão Tipográfica», do mesmo autor, a ser edi-
tada por êste Serviço de Documentação. 
ESQUEMA A

\section{Composição}

Revisão

Impressão

caixa

Acabamento

minerva

ESQUEMA B

\begin{tabular}{llc}
\hline $\begin{array}{l}\text { Composição } \\
\text { caixa } \\
\text { linotipo }\end{array}$ & $\begin{array}{c}\text { Revisão } \\
\text { plana }\end{array}$ & $\begin{array}{c}\text { Impressão } \\
\text { Acabamento }\end{array}$ \\
\hline & minerva \\
cilindrica
\end{tabular}

ESQUEMA C

\begin{tabular}{lllll}
\hline Composição & Gravura & Revisão & Estereotipìa & Impressão \\
caixa & plana & & plana & minerva \\
linotipo & roto & & roto & cilindrica \\
tituleire & & & rotativa \\
monotipo & & & &
\end{tabular}

Encadetnação

Esquemas mais desenvolvidos podem ainda comportar outros setores, como a Litografia, com o seu excelente processo offset, e outros.

\section{ANDAMENTO DA MATÉRIA}

Passamos a descrever, a seguir, o andamento da matéria destinada à publicação, através dos diferentes setores gráficos, ora como livro, ora como jornal.

A medida que vai percorrendo as diversas oficinas, a dita matéria também vai recebendo diversas denominações: aqui é original, desenho, foto; ali é paquê, página (página de composição), prova; mais adiante é fôrma e telha, até que, afinal, ganha a sua denominação definitiva: livro ou jornal. 


\section{O LIVRO}

Quando os originais de um livro são enviados a um estabelecimento gráfico, devem ir prontos para ser compostos: dactilografados de um só lado do papel, espaço dois, laudas uniformes e numeradas, revistas pelo autor ou responsável.

É muito importante para qualquer emprêsa gráfica que os originais sejam entregues nessas condições, porque assim as atividades oficinais ficam grandemente facilitadas, desde o cálculo do número de páginas do volume e da quantidade total de papel necessária até o labor dos diferentes setores, o que tudo se traduz por grande economia de trabalho e de tempo.

Ao darem entrada na Composição, os originais recebem uma marcação (isto é, indicações sôbre os diversos tipos, corpos e medidas que deverão ser usados na obra) e uma retranca.

Retrancar originais é marcá-los com letras, algarismos ou ambas as coisas, para fins de identificação.

No jornal, por exemplo, onde as retrancas são menos simples que no livro, convencionou-se que a primeira página seja sempre página $A$; a segunda página, a página $B$; a terceira página, a

Do mesmo modo quanto aos artigos de uma página: o pri-

Assim, se um artigo de jornal se compuser de dez laudas e fôr o primeiro da primeira página, as suas laudas serão retrancadas da seguinte maneira: AA 1, AA 2, AA 3, etc., até AA 10x, a última lauda recebendo um $\mathrm{x}$, que se lê simplesmente pé e
assinala a lauda final do artigo.

Os artigos seguintes receberão

tas: $\mathrm{AB} 1, \mathrm{AB} 2, \mathrm{AB} 3$, etc., $\mathrm{AC}$, portanto, retrancas como es$\mathrm{AD} 2, \mathrm{AD} 3$, etc., tôd, etc., $\mathrm{AC} 1, \mathrm{AC} 2, \mathrm{AC} 3$, etć.; $\mathrm{AD} 1$, As retrancas da até $x$, que é a lauda final do artigo. com a letra $\mathrm{B}$; as da segunda página começarão, dessa maneira, letra D, etc., etc.

No caso de se tratar de livro, as suas laudas também serão retrancadas de maneira semelhante, levando, porem à última uma só retranca: HB 1, levando, porém, da primeira supondo-se que o livro tenha ê, $\mathrm{HB} 2, \mathrm{HB} 3$, etc., até $\mathrm{HB} 350 \mathrm{x}$, significando, na hipótese, as ine número de páginas, as letras HB do Brasil, por exemplo. 
Uma vez retrancados, os originais são distribuidos aos compositores de caixa, monotipo ou linotipo, conforme o caso, e remetidos à Gravura aquêles que contiverem desenhos ou fotos, de onde voltarão à Composição com as respectivas provas, para dai serem enviados à Revisão, agora já com as legendas correspon-
dentes.

Os compositores produzem os paquês, dos quais se tiram provas, as provas de paquê, que, anexas aos originais, recebem
a retranca dêstes.

Depois, originais e provas são remetidos à Revisão, onde passam a ser distribuidos por diversas mesas de revisão, constituidas por dois revisores, um que lê a prova fazendo as êmendas e outro que acompanha essa leitura pelo original, leitura que é freqüentemente interrompida para a retificação de lapsos tipográficos e outros. Terminada a revisão dessas provas, faz-se das mesmas nova revisão, se a natureza do trabalho assim o exigir, neste caso passando a ler o revisor que antes acompanhou e a
acompanhar o revisor que antes leu.

Assim que revisadas, voltam essas primeiras provas à Composição (juntamente com os originais, se houver omissão de linhas ou trechos), ai sendo emendados os paquês e tiradas segundas provas que, com as primeiras, são de nôvo enviadas à Revisão.

Neste setor, decalcam-se, então, as segundas provas.

Decalcar, aqui, significa comparar, por sobreposição, a primeira prova revisada com a segunda prova emendada, para veri-
ficar se tôdas as correções foram feitas.

Faz-se êsse decalque sobrepondo as linhas da primeira prova as linhas da segunda prova, confrontando as letras, palavras ou trechos revisados da primeira com as correspondentes letras, palavras ou trechos emendados da segunda, no caso de se tratar de composição de caixa ou monotipo, e ainda relendo as linhas emendadas da segunda e comparando as demais linhas da primeira com as demais linhas da segunda, a fim de prevenir possiveis extravios ou transposições, no caso de se tratar de composição de linotipo.

Além disso, para maior segurança do trabalho, é sempre aconselhável proceder a mais uma releitura da segunda prova.

Se se concluir, após o decalque e a releitura, que tôdas as emendas foram corretamente feitas e, portanto, que a segunda prova é uma prova "limpa" ou sem erros, a Composição não mais precisará mandar prova dêsse paquê; se, ao contrário, ainda hou- 
ver emendas, o referido setor ainda deverá mandar mais provas, até se obter uma prova "limpa".

Quando remetidas à Revisão as provas de página, faz-se o seu decalque com o auxilio das provas de paquê respectivas, a fim de se verificar se delas não consta alguma omissão ou transposição, bem como se os demais detalhes, como os dizeres das cabeças, a numeração das páginas, o encadeamento do texto, etc. foram devidamente observados.

Uma vez decalcadas e consideradas "limpas", voltam as provas de página à Composição, de onde as páginas de composição correspondentes, já sôbre os porta-páginas, são posteriormente enviados à Impressão.

Neste setor, as páginas de composição são depositadas nos mármores ou mesas de imposição, onde, logo que impostas e engradadas, vão constituir as fôrmas, nome que se dá à composição pronta para entrar em máquina.

Imposição é a disposição, nos mármores, das páginas de composição destinadas à impressão, de modo que, depois de impressas, apareçam corretamente nos cadernos.

Engradação é o apêrto, por meio de guarnições e cunhos, das páginas de composição já impostas, em caixilhos de ferro
chamados ramas.

Desde que colocadas na impressora, destas fôrmas também se tiram provas, as provas de máquina, numa só fôlha de papel, impressa quase sempre de ambos os lados, a qual é enviada dobrada à Revisão, geralmente constituindo um caderno de 8 , 16 ou 32 páginas, a fim de que êste setor, além de decalcar a prova de máquina por meio das provas de página respectivas, ainda possa verificar se a ordem das páginas e demais pormenores estão corretos.

Nada mais havendo a emendar, estando "limpa", portanto, esta última prova, tem início a impressão.

Terminada esta, as fôlhas impressas são em seguida enviadas à Encadernação e daqui, após grampeadas e capeadas ou costuradas e encadernadas, isto é, já constituidas em folheto ou livro, remetidas ao seu destino.

\section{O JORNAL}

A medida que os originais de um número de jornal vão dando entrada nas oficinas, aí também vão sendo distribuidos aos compositores de caixa, linotipo e tituleira, de acôrdo com o espelho 
das retrancas, que é a relação de tôdas as retrancas do número do jornal e cuja finalidade é orientar e controlar o trabalho.

Daí por diante e até as provas de paquê "limpas", o andamento da matéria do jornal é pràticamente idêntico ao do livro, processando-se do mesmo modo os trabalhos da Composição e da Revisão, embora em ritmo acelerado, dado o seu caráter sempre urgente.

A partir de então, porém, o andamento da matéria do jornal passa a diferençar-se do do livro.

Assim é que, uma vez "limpas" as provas de paquê, os paquês respectivos, são paginados e as páginas de composição daí resultantes impostas e engradadas na própria Composição, ao contrário do que acontece com o livro, cujas páginas de composição, como vimos, são impostas e engradadas na Impressão.

Dessas páginas de composição, tiram-se, então, as últimas provas, que são decalcadas no local por meio das provas de paquê respectivas (é o que se chama têrça de página), trabalho êsse a cargo de revisores ai destacados.

Depois de realizada esta parte do trabalho e estando as provas de página "limpas", as ramas são enviadas à Estereotipia.

Neste setor, com o auxilio de uma calandra ou prensa e fôlhas de papelạ̃o especial, os flãs, das fôrmas contidas nas ditas ramas se tiram matrizes que, depois de colocadas em fundidoras apropriadas, permitem a obtenção das telhas, que nada mais são que chapas curvas de metal que contêm a reprodução das fôrmas em todos os seus detalhes.

A fim de eliminar os riscos do transporte das ramas de uma oficina para outra, muitos estabelecimentos gráficos instalam as calandras ou prensas na Composição, dai saindo as matrizes, em vez das ramas, para a Estereotipia.

Uma vez prontas, as telhas são enviadas à Impressão, onde, montadas na rotativa, vão imprimir as fôlhas.

Estas são, desde logo, entregues à circulação, cortadas e dobradas (e às vêzes até grampeadas), conforme saem da rotativa, isto é já constituidas em jornai.

Como se vê, o revisor está sempre presente em quase todos os processos gráficos, o que comprova, de maneira indiscutivel, a natureza indispensável e relevante do seu trabalho. 


\section{DIAGRAMA}

DO

ANDAMENTO DA MATERIA

CONFORME O ESQUEMA C

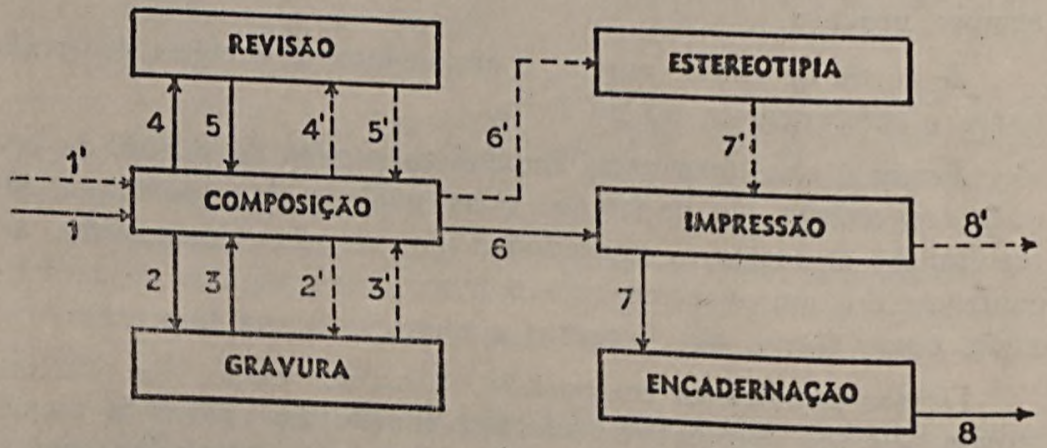

CONVENÇOES

\begin{tabular}{l|l}
\hline - Original (com desenho ou foto). & $\mid-\ldots .$. \\
2 - Original (só desenho ou foto). & 2 - Original (com desenho ou foto). \\
3 - Original e prova. & 3 - Original e prova. \\
- Original e prova. Prova e prova. & 4 - Original e prova. Prova e prova. \\
5 - Original e prova. Prova e prova. & 5 - Original e prova. Prova e prova. \\
6 - Página. & 6 - Rama. \\
7 - Fòlha. & 7 - Telha. \\
8 - Livro. & 8 - Jornal.
\end{tabular}

